\title{
How do patient demographics, time-related variables, reasons for cancellation, and clinical procedures affect frequency of same-day operating room surgery cancelation? A maximum likelihood method
}

Omar B. Da'ar ${ }^{1,2^{*}}$ and Talal Al-Mutairi ${ }^{3}$

\begin{abstract}
Background: Cancelation of same-day surgery is a common global problem, wasting valuable hospitals' operating room (OR) times and imposing significant economic costs. There is limited evidence to support the association between frequency of same-day surgery cancelation and patient demographics, time-related variables, healthcare provider reasons for cancelation, and clinical procedures in Saudi Arabia. The aim of this study was to explore this relationship, providing an understanding of the local context.

Methods: A retrospective cross-sectional study that retrieved medical records to examine the association between the frequency of same-day surgery cancelation and covariates including patient demographics, time-related variables, healthcare provider reason for cancelation, and clinical procedures. The data covered from January 2014 to December 2014 at King Fahad National Guard Hospital in Riyadh. We considered 440 patients that met the inclusion criteria for final analysis. The cancelation was regarded less frequent if a patient canceled once in the 12 months and more frequent if a patient canceled two times or more in the same period. We used descriptive statistics to summarize data and employed a probit regression to estimate the association of frequency of same-day surgery cancelation and covariates via maximum likelihood method. King Abdullah International Medical Research Center granted the institutional approval.

Results: Our study suggests that while reasons of unavailability of OR time were associated with less frequent same-day surgery cancelation, scheduling issues were linked to more frequent cancelations, compared with reasons for patients being unwell on the day of surgery. Waiting time of more than six hours and morning sessions were associated with less frequent cancelations compared to shorter waiting time and afternoon sessions. Compared to general procedures, specialized clinical procedures were associated with cancelations that are more frequent. Further, female patients were more likely to have more cancelations. Finally, being married was associated with the less frequent cancelation of sameday surgery.

(Continued on next page)
\end{abstract}

\footnotetext{
* Correspondence: daaro@ksau-hs.edu.sa; odaar@smumn.edu;

obdaar@hotmail.com

${ }^{1}$ Department of Health Systems \& Quality Management, College of Public Health \& Health Informatics, King Saud Bin Abdulaziz University for Health Sciences, National Guard Health Affairs (NGHA), Riyadh, Saudi Arabia

${ }^{2}$ Graduate School of Professional Studies, St. Mary's University of Minnesota,

Minneapolis, MN, USA

Full list of author information is available at the end of the article
}

(c) The Author(s). 2018 Open Access This article is distributed under the terms of the Creative Commons Attribution 4.0 International License (http://creativecommons.org/licenses/by/4.0/), which permits unrestricted use, distribution, and reproduction in any medium, provided you give appropriate credit to the original author(s) and the source, provide a link to the Creative Commons license, and indicate if changes were made. The Creative Commons Public Domain Dedication waiver (http://creativecommons.org/publicdomain/zero/1.0/) applies to the data made available in this article, unless otherwise stated. 
(Continued from previous page)

Conclusion: Our findings provide evidence of determinants of the frequency of same-day surgery cancelations. This study draws several important implications for hospitals, especially on optimal utilization of resources and minimization of same-day surgery cancellations. The study also offers several recommendations that we believe will spur future research.

Keywords: Same-day surgery cancelation, Frequency of cancelation, Probit regression, Saudi Arabia

\section{Background}

Same-day operating room (OR) surgery cancellation of elective cases is a common global problem in hospitals [1-6] which wastes valuable operating-room time [5]. Many studies have found that reasons for same-day cancellations were mostly related to patients, medical conditions, surgeons, administrative and anesthesia issues $[1,6,7]$. Cancelations of same-day surgery due to these and other reasons frequently occur in hospitals, causing significant economic costs [8] with implications for management in terms of material consumption, medications, and human resources among other factors, as well as causing inconvenience for patients and families [3, 9]. Late cancelations of elective operations have significant psychological, social and financial implications for patients and their families [10]. Hospitals continue to face challenges given that the overall rate of cancellation of elective operations on the day of surgery varies, ranging from 5 to $40 \%$ of planned electives [8, 11-16].

Studies in Middle East countries indicate that the issue of same-day cancelation of surgery cases is common $[4,6$, 17]. A study in Qatar, for instance, showed late cancelation of up to $15 \%$ for outpatient and $13 \%$ for inpatient [4]. A study in Saudi Arabia indicated canceled same-day surgery of up to $24 \%$ [6], while another in the country showed $8 \%$ of surgery cases canceled [17]. Another study in Jordan showed that while Day Unit accounted for $28 \%$ of elective operations cancelations, impatient cancelation accounted for $73 \%$, with patient non-attendance and unavailability of hospital beds being the most common reasons [18].

While previous studies have delved into reasons for the day of surgery cancelation, the relationship between the frequency of same-day surgery cancelation, patient demographics, time-related variables, healthcare provider reason for cancelation, and clinical procedures for which a patient had an appointment, have not, at least according to our knowledge, previously been studied in Saudi Arabia. The present study explores this relationship using a combination of statistical methods to estimate the probability of frequency of same-day surgery cancelation. This analysis is noteworthy for two reasons. The present study is the first such analysis of its kind in Saudi Arabia, at least to the best of our knowledge. It is also the first of its kind in that context to employ maximum likelihood estimation with a probit model.

\section{Methods}

A retrospective cross-sectional study that examined medical records of the frequency of cancelation of patients with same-day surgery schedules. The aim was to examine the association between the frequency of same-day surgery cancelation and covariates including patient demographics, time-related variables, healthcare provider reason for cancelation, and clinical procedures for which a patient had an appointment. The retrieved records covered 12 months period from January 2014 to December 2014 at King Fahad National Guard Hospital in Riyadh in the King Abdulaziz Medical City (KFNGH-KAMC).

We considered 440 patients that met the inclusion criteria for final analysis. Information retrieved included time-related variables such as waiting time before cancelation, availability of operating time, and scheduling. Other variables retrieved included reasons for cancelation, clinical procedures, the frequency of cancelation, and patient demographic profiles. The frequency of cancelation was the response variable of interest. We constructed a binary variable where cancelation of same-day surgery was defined as less frequent if a patient canceled once in 12 months and more frequent if a patient canceled two times or more in the same period. We descriptively summarized all variables of interest and employed a probit regression to estimate the probability of frequency of same-day surgery cancelations with respect to key independent variables using the method of maximum likelihood. The Institutional Review Board (IRB) of King Abdullah International Medical Research Center (KAIMRC) with protocol number-Ref. SP15/148 approved this study.

\section{Statistical analysis}

With a consent, data were retrieved from medical records and then transferred to STATA Statistical Software Release 12 for analysis [19]. We used descriptive statistics such as means and standard deviations to summarize quantitative variables and frequencies and percentages to characterize categorical variables. We conducted a probit regression analysis by constructing a binary of whether or not patients frequently canceled same-day surgery. We controlled for various factors associated with this probability outcome and descriptively summarized them in Tables 1 and 2. 
Table 1 Patient demographics and time-related variables $(N=440)$

\begin{tabular}{|c|c|c|}
\hline Characteristics & Levels & N (\%) \\
\hline Age (Mean \pm SD) & & $\begin{array}{l}46.2 \pm \\
19.7\end{array}$ \\
\hline $\begin{array}{l}\text { Waiting time to same-day cancelation } \\
\text { in hours (Mean } \pm \text { SD) }\end{array}$ & & $3.6 \pm 2.3$ \\
\hline $\begin{array}{l}\text { Waiting time to same-day cancelation } \\
\text { in hours }>6 \text { hours }\end{array}$ & $\begin{array}{l}\text { Waiting time }> \\
6 \text { hours }\end{array}$ & $61(13.9)$ \\
\hline Age & $\geq 18$ Years & $413(93.9)$ \\
\hline Session of cancelation, n (\%) & $A M$ & $389(88.4)$ \\
\hline Gender, n (\%) & Male & $213(48.4)$ \\
\hline $\begin{array}{l}\text { Frequency of same-day cancelation } \\
\text { in } 12 \text { months, } \mathrm{n}(\%)\end{array}$ & Once & $370(84.1)$ \\
\hline Resident, n (\%) & Riyadh & $368(83.6)$ \\
\hline Nationality, n (\%) & National & $392(89.1)$ \\
\hline \multirow[t]{5}{*}{ Marital status } & Married & $278(63.3)$ \\
\hline & Single & $114(26)$ \\
\hline & Divorced & $6(1.4)$ \\
\hline & Widowed & $18(4.1)$ \\
\hline & Unknown & $23(5.2)$ \\
\hline \multicolumn{3}{|l|}{ Season } \\
\hline & Winter & $84(19.1)$ \\
\hline & Fasting & $19(4.3)$ \\
\hline & Summer & $104(23.6)$ \\
\hline & Spring & $154(35.0)$ \\
\hline & Fall/Autumn & 79 (18.0) \\
\hline
\end{tabular}

\section{Results}

\section{Descriptive statistics}

Tables 1 and 2 summarize the descriptive statistics of key variables of interest. Among the 440 patients who canceled same-day surgery, 213 (48.4\%) were male. The mean age was $42.3 \pm 16.7$ and supermajority 413 (93.9\%) of the patients were 18 years or older. The mean waiting time before cancelation of same-day surgery was $3.6 \mathrm{~h}$ ( \pm 2.3 standard deviation). Waiting time before cancelation of same-day surgery was greater than $6 \mathrm{~h}$ for $13.9 \%$ of the patients. Of the patients who canceled same-day surgery, 389 (88.4\%) did so in the morning session. Majority of the patients, 392 (89.1\%) were Saudi nationals, 368 (83.6\%) live in Riyadh, and 278 (63.3\%) were married. Eighty-four percent of patients canceled same-day surgery once in 12 months, while $16 \%$ of them canceled more than once in the same period. Nearly a fifth (19.1\%) and a fourth (24\%) of the patients had canceled same-day surgery during winter and summer respectively. Saudi National Guard (SANG) staff and their dependents constituted nearly three-fourths (76\%) of patients canceling same-day surgery. Reasons for cancelation of same-day surgery also included unavailability of OR time (12.7\%), scheduling issues (2.7\%), uncontrolled
Table 2 Patient eligibility, reasons for cancelation, and clinical procedures $(N=440)$

\begin{tabular}{|c|c|c|}
\hline Characteristics & Levels & $N(\%)$ \\
\hline \multicolumn{3}{|l|}{ Eligibility } \\
\hline & Others & $13(3.0)$ \\
\hline & $\begin{array}{l}\text { Saudi National Guard } \\
\text { (SANG) staff }\end{array}$ & $100(22.7)$ \\
\hline & SANG dependents & $230(52.3)$ \\
\hline & KFH employee & $15(3.4)$ \\
\hline & KFH employee dependent & $14(3.2)$ \\
\hline & Exceptions Saudi & $34(7.7)$ \\
\hline & Exceptions 7 diseases & $15(3.4)$ \\
\hline & Ineligible/out-of-pocket & $19(4.3)$ \\
\hline \multicolumn{3}{|c|}{ Reason for cancelation } \\
\hline & Others & $115(26.1)$ \\
\hline & Aspirin intake & $14(3.2)$ \\
\hline & No O.R time & $56(12.7)$ \\
\hline & Not fasting & $13(3.0)$ \\
\hline & Not indicated & $51(11.6)$ \\
\hline & Scheduling issues & $12(2.7)$ \\
\hline & $\begin{array}{l}\text { Uncontrolled blood } \\
\text { pressure }\end{array}$ & $37(8.4)$ \\
\hline & $\begin{array}{l}\text { Uncontrolled blood } \\
\text { sugar }\end{array}$ & $31(7.1)$ \\
\hline & Unwell on day of procedure & $79(18)$ \\
\hline & Patient refusal & $32(7.3)$ \\
\hline \multicolumn{3}{|c|}{ Procedure for same-day surgery } \\
\hline & Others & $234(53.2)$ \\
\hline & $\begin{array}{l}\text { Extracapsular cataract } \\
\text { extraction \& \& Intra } \\
\text { Ocular Lens (ECCE IOL) }\end{array}$ & $33(7.5)$ \\
\hline & Excision Sinus & $10(2.3)$ \\
\hline & Hernia repair & $49(11.1)$ \\
\hline & Lap Cholecystetomy & $30(6.8)$ \\
\hline & $\begin{array}{l}\text { Phacoemulsification \& } \\
\text { Intra Ocular Lens } \\
\text { (Phaco IOL) }\end{array}$ & $45(10.2)$ \\
\hline & S/R wisdom teeth & $16(3.6)$ \\
\hline & Septoplasty & $13(3.0)$ \\
\hline & Tympanoplasty & $10(2.3)$ \\
\hline
\end{tabular}

blood pressure (8.4\%), uncontrolled blood sugar (7.1\%), unwell on day of procedure $(18 \%)$, and patient refusal (7.3\%) among other reasons.

\section{Probit results and analysis}

Table 3 shows parameter estimates for the probit model, computed using the method of maximum likelihood estimation. A positive (negative) sign of the coefficients implies that an increase (decrease) in the explanatory 
Table 3 Probit Regression: Probability of frequency of cancelation

\begin{tabular}{|c|c|c|c|c|c|c|}
\hline \multicolumn{3}{|l|}{ Probit regression } & \multicolumn{4}{|c|}{ No. of obs $=357$} \\
\hline & & & \multicolumn{4}{|c|}{ Wald chi2(34) $=42.48$} \\
\hline & & & \multicolumn{4}{|c|}{ Prob $>$ chi2 $=0.1509$} \\
\hline \multicolumn{3}{|l|}{ Log pseudo likelihood =- 138.506} & \multicolumn{4}{|c|}{$R^{2}=0.1674$} \\
\hline $\begin{array}{l}\text { Dependent variable (Frequency of cancelation: } \\
1=\text { Once, } 0=\text { More than once) }\end{array}$ & Coefficient & Robust std. Error & Z & $P>z$ & {$[95 \%$ Co } & rval] \\
\hline \multicolumn{7}{|l|}{ A } \\
\hline Waiting time & \multicolumn{6}{|c|}{ (Reference is < $6 \mathrm{~h}$ ) } \\
\hline Waiting time $>6 \mathrm{~h}$ & 0.089 & 0.042 & 2.1 & $0.036^{* * *}$ & 0.006 & 0.171 \\
\hline Age & \multicolumn{6}{|c|}{ (reference $=$ child $)$} \\
\hline Adult & 0.018 & 0.437 & 0.04 & 0.967 & -0.839 & 0.875 \\
\hline Session & \multicolumn{6}{|c|}{ (reference $=$ Afternoon) } \\
\hline Morning session & 0.605 & 0.278 & 2.17 & $0.030^{* * *}$ & 0.060 & 1.150 \\
\hline Gender & \multicolumn{6}{|c|}{ (reference $=$ Female) } \\
\hline Male & 0.558 & 0.265 & 2.11 & $0.035^{* * *}$ & 0.039 & 1.078 \\
\hline Residence & \multicolumn{6}{|c|}{ (reference $=$ outside city) } \\
\hline Riyadh Resident & -0.049 & 0.255 & -0.19 & 0.849 & -0.548 & 0.451 \\
\hline Nationality & \multicolumn{6}{|c|}{ (reference $=$ non-Saudi) } \\
\hline Saudi & -1.805 & 0.566 & -3.19 & $0.001^{* * *}$ & -2.915 & -0.695 \\
\hline Season & \multicolumn{6}{|c|}{ Winter (reference) } \\
\hline Fasting & 1.045 & 0.599 & 1.74 & 0.081 & -0.130 & 2.219 \\
\hline Summer & 0.397 & 0.245 & 1.62 & 0.106 & -0.084 & 0.877 \\
\hline Spring & 0.642 & 0.255 & 2.52 & $0.012^{* * *}$ & 0.143 & 1.142 \\
\hline Fall/Autumn & 0.350 & 0.263 & 1.33 & 0.183 & -0.165 & 0.866 \\
\hline Marital status & \multicolumn{6}{|c|}{ Married (reference) } \\
\hline Single & 0.012 & 0.237 & 0.05 & 0.96 & -0.453 & 0.477 \\
\hline Divorced & -0.451 & 0.454 & -0.99 & 0.321 & -1.341 & 0.439 \\
\hline Widowed & -0.139 & 0.369 & -0.38 & 0.707 & -0.863 & 0.585 \\
\hline Unknown & -1.039 & 0.427 & -2.43 & $0.015^{* * *}$ & -1.877 & -0.202 \\
\hline Constant & 1.831 & 0.800 & 2.29 & 0.022 & 0.264 & 3.399 \\
\hline \multicolumn{7}{|l|}{ B } \\
\hline Eligibility & \multicolumn{6}{|c|}{ Saudi dependent (reference) } \\
\hline Others & -1.258 & 0.466 & -2.7 & $0.007^{* * *}$ & -2.172 & -0.344 \\
\hline Saudi & -0.754 & 0.320 & -2.36 & $0.018^{* * *}$ & -1.381 & -0.128 \\
\hline Employee & -1.432 & 0.619 & -2.31 & $0.021^{* * *}$ & -2.646 & -0.219 \\
\hline Employee dependents & 0.221 & 0.577 & 0.38 & 0.701 & -0.910 & 1.353 \\
\hline Exceptions Saudi & -0.511 & 0.342 & -1.49 & 0.135 & -1.182 & 0.160 \\
\hline Exceptions 7 diseases & -1.096 & 0.727 & -1.51 & 0.132 & -2.521 & 0.329 \\
\hline Ineligible/out-of-pocket & -1.301 & 0.691 & -1.88 & $0.06^{* * *}$ & -2.656 & 0.054 \\
\hline Procedure & \multicolumn{6}{|c|}{ Hernia (reference) } \\
\hline Others & -0.233 & 0.325 & -0.72 & 0.472 & -0.870 & 0.403 \\
\hline ECCE IOL & -0.019 & 0.447 & -0.04 & 0.966 & -0.895 & 0.857 \\
\hline Excision Sinus & 0.000 & (empty) & & & & \\
\hline Lap Cholecystetomy & -0.571 & 0.455 & -1.26 & 0.209 & -1.463 & 0.321 \\
\hline Phaco IOL & -0.645 & 0.379 & -1.7 & $0.089^{*}$ & -1.388 & 0.098 \\
\hline
\end{tabular}


Table 3 Probit Regression: Probability of frequency of cancelation (Continued)

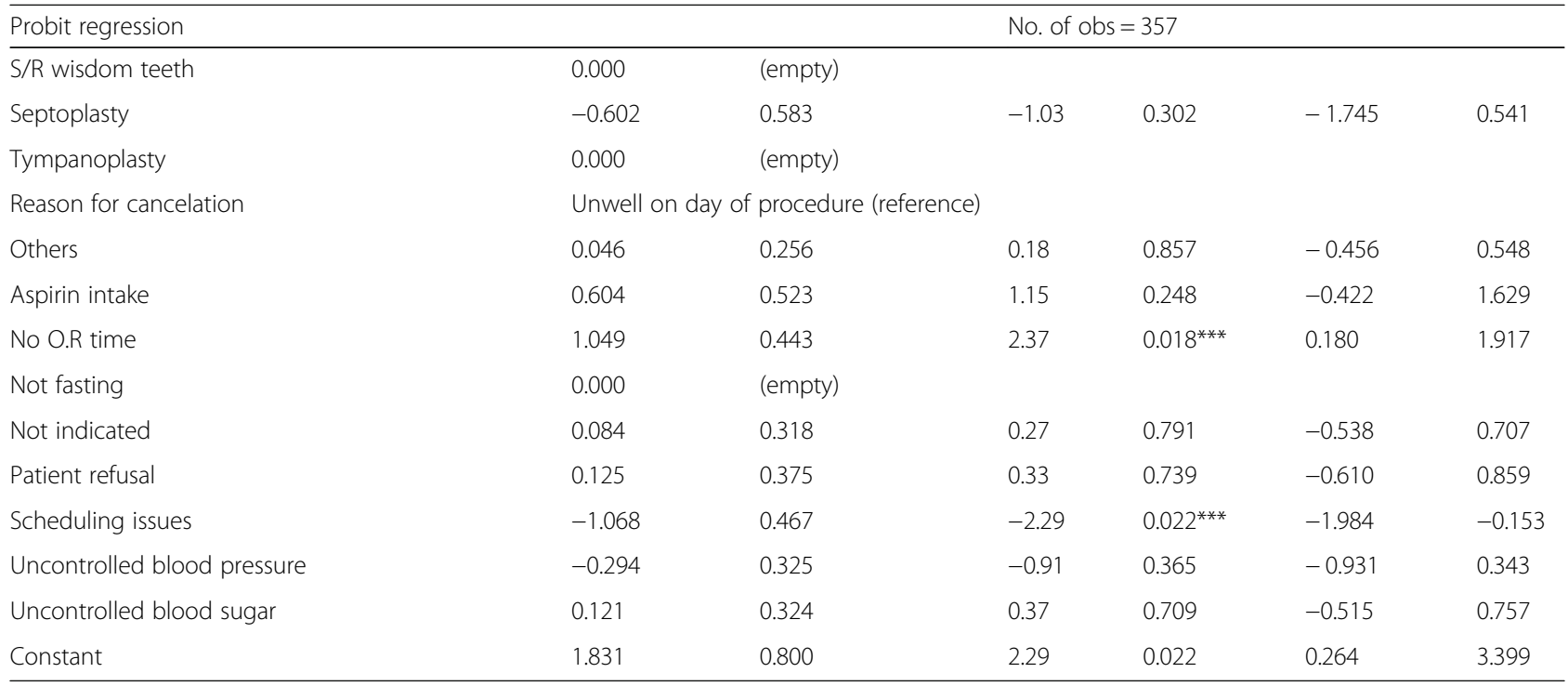

Significant at ${ }^{* * *} p<0.01 ;{ }^{* *} p<.05$

Significant at ${ }^{* * *} p<0.01 ;{ }^{* *} p<.05 ;{ }^{*} p<0.1$

variable leads to an increase (decrease) in the predicted probability of frequently canceling same-day surgery elective appointment. It is important to note that our dependent binary variable is reversed-coded $(1=$ canceled once; $0=$ canceled more than once). Therefore, we should interpret negative coefficients or marginal effects as increasing the frequency of same-day surgery cancelation. However, while probit estimation reveals the probabilities and/or the changes in probability, the qualitative nature of such results may present a challenge in interpreting the coefficients. To take into consideration this challenge and give a quantitative interpretation of the probit results, we further present marginal effects as probability units in Table 4.

\section{Marginal effects}

In order to give a quantitative interpretation of the probit results, we present average or marginal effects as probability units (Table 4). The probability of frequency of same-day surgery cancelation in a morning session was 0.16 less than an afternoon $(P=0.03<0.05)$. The probability of frequency of same-day surgery cancelation by a male patient was 0.12 less than a female patient, while the probability of frequent cancelation of a same-day surgery by a Saudi patient was 0.17 more than a non-Saudi $(P=0.035<0.05$; $(P=0.001<0.05$ respectively). The probability of same-day surgery cancelation during the month of fasting was 0.29 more than during winter season. This result was however not statistically significant. The probability of frequency of same-day surgery cancelation if patients waited for more than $6 \mathrm{~h}$ was 0.02 less than if patients waited for less than $6 \mathrm{~h}$ before surgery
$(P=0.036<0.05)$. The probability of frequency of same-day surgery cancelation of a patient whose marital status is unknown, or not reported was 0.33 more compared to married patients $(P=0.015<0.05)$. Table 4 depicts the summary of these results.

As presented in Table 4, the probability of same-day surgery cancelation for a patient scheduled for Phaco IOL procedure is 0.17 more than a patient scheduled for Hernia. While this result is not statistically significant, there is evidence that procedures such as Phaco IOL are more frequently canceled, especially in the ophthalmic literature due to reasons for a patient not being fit for local anesthesia or pre-existing conditions [20]. The probability of same-day surgery canceled more frequently for OR time availability is 0.14 less than if the reason was patient being unwell on the day of the procedure $(P=0.018$ $<0.05)$. However, the probability of same-day surgery canceled more frequently for scheduling issues is 0.34 more than if the reason was patient being unwell on the day of the procedure $(P=0.022<0.05)$. The probability of same-day surgery canceled more frequently is higher among SANG patients, hospital employees, and patients who are ineligible or pay out-of-pocket compared to dependents of SANG members.

\section{Discussion}

In this study, we attempted to examine the association between the probability of frequency of same-day surgery cancelation and various covariates such as patient demographics, time-related variables, healthcare provider reasons for cancelation, and clinical procedures for which patients had appointments. This relationship has not hitherto been studied either prospectively or 
Table 4 Marginal effects: Patient demographics and Time-related variables

\begin{tabular}{|c|c|c|c|c|c|c|c|}
\hline \multirow{2}{*}{\multicolumn{3}{|c|}{$\begin{array}{l}\text { Probit regression } \\
\text { Log pseudo likelihood }=-138.506\end{array}$}} & \multicolumn{3}{|c|}{ No. of obs $=357$} & \multirow{2}{*}{\multicolumn{2}{|c|}{$\begin{array}{l}\text { Wald chi2 }(34)=42.48 \\
\mathrm{~B} 2=0.1674\end{array}$}} \\
\hline & & & \multicolumn{3}{|c|}{ Prob $>$ chi2 $=0.1509$} & & \\
\hline $\begin{array}{l}\text { Dependent variable }=\text { Frequency of cancelation } \\
(1=\text { Once, } 0=\text { More than once })\end{array}$ & $\mathrm{dF} / \mathrm{dx}$ & Robust Std. Err. & Z & $P>z$ & $x$-bar & & \\
\hline Waiting time & 0.019 & 0.009 & 2.1 & $0.036^{* *}$ & 3.630 & 0.002 & 0.036 \\
\hline Adult & 0.004 & 0.094 & 0.04 & 0.967 & 0.944 & -0.180 & 0.188 \\
\hline Morning session & 0.161 & 0.086 & 2.17 & $0.03^{* *}$ & 0.880 & -0.008 & 0.330 \\
\hline Male & 0.115 & 0.053 & 2.11 & $0.035^{* *}$ & 0.459 & 0.011 & 0.220 \\
\hline Riyadh Resident & -0.010 & 0.052 & -0.19 & 0.849 & 0.832 & -0.112 & 0.091 \\
\hline National & -0.168 & 0.028 & -3.19 & $0.001^{* *}$ & 0.902 & -0.223 & -0.113 \\
\hline Fasting & -0.293 & 0.198 & -1.74 & 0.081 & 0.204 & -0.682 & 0.095 \\
\hline Summer & -0.163 & 0.169 & -1.1 & 0.27 & 0.235 & -0.494 & 0.168 \\
\hline Spring & -0.091 & 0.143 & -0.68 & 0.497 & 0.339 & -0.371 & 0.189 \\
\hline Fall/Autumn & -0.183 & 0.183 & -1.17 & 0.244 & 0.182 & -0.542 & 0.176 \\
\hline Single & 0.002 & 0.050 & 0.05 & 0.96 & 0.218 & -0.095 & 0.100 \\
\hline Divorced & -0.119 & 0.142 & -0.99 & 0.321 & 0.017 & -0.398 & 0.160 \\
\hline Widowed & -0.031 & 0.089 & -0.38 & 0.707 & 0.048 & -0.206 & 0.143 \\
\hline Unknown & -0.326 & 0.165 & -2.43 & $0.015^{* *}$ & 0.045 & -0.649 & -0.003 \\
\hline \multicolumn{8}{|l|}{ Surgical procedures (reference $=$ hernia) } \\
\hline Others & -0.049 & 0.066 & -0.72 & 0.472 & 0.557 & -0.178 & 0.081 \\
\hline ECCE IOL & -0.004 & 0.096 & -0.04 & 0.966 & 0.092 & -0.192 & 0.184 \\
\hline Lap Cholecystetomy & -0.153 & 0.144 & -1.26 & 0.209 & 0.081 & -0.435 & 0.129 \\
\hline Phaco IOL & -0.174 & 0.120 & -1.7 & 0.089 & 0.120 & -0.410 & 0.062 \\
\hline Septoplasty & -0.167 & 0.198 & -1.03 & 0.302 & 0.034 & -0.555 & 0.221 \\
\hline \multicolumn{8}{|c|}{ Reasons for cancelation (reference $=$ Unwell on day of surgery) } \\
\hline Others & 0.010 & 0.053 & 0.18 & 0.857 & 0.235 & -0.093 & 0.113 \\
\hline Aspirin intake & 0.091 & 0.051 & 1.15 & 0.248 & 0.039 & -0.010 & 0.191 \\
\hline No O.R time & 0.139 & 0.030 & 2.37 & $0.018^{* *}$ & 0.126 & 0.080 & 0.199 \\
\hline Not indicated & 0.017 & 0.063 & 0.27 & 0.791 & 0.120 & -0.105 & 0.140 \\
\hline Patient refusal & 0.025 & 0.070 & 0.33 & 0.739 & 0.070 & -0.112 & 0.162 \\
\hline Scheduling issues & -0.341 & 0.181 & -2.29 & $0.022^{* *}$ & 0.028 & -0.696 & 0.015 \\
\hline Uncontrolled blood pressure & -0.071 & 0.088 & -0.91 & 0.365 & 0.098 & -0.242 & 0.101 \\
\hline Uncontrolled blood sugar & 0.024 & 0.061 & 0.37 & 0.709 & 0.084 & -0.095 & 0.143 \\
\hline \multicolumn{8}{|l|}{ Eligibility (reference $=$ Saudi NGHA dependent } \\
\hline Others & -0.415 & 0.179 & -2.7 & $0.007^{* * *}$ & 0.031 & -0.765 & -0.065 \\
\hline Saudi NGHA & -0.194 & 0.093 & -2.36 & $0.018^{* *}$ & 0.241 & -0.377 & -0.012 \\
\hline NGHA Employee & -0.483 & 0.233 & -2.31 & $0.021^{* *}$ & 0.028 & -0.939 & -0.027 \\
\hline NGHA Employee dependents & 0.041 & 0.094 & 0.38 & 0.701 & 0.034 & -0.143 & 0.226 \\
\hline Exceptions Saudi & -0.134 & 0.105 & -1.49 & 0.135 & 0.078 & -0.341 & 0.072 \\
\hline Exceptions 7 diseases & -0.350 & 0.283 & -1.51 & 0.132 & 0.036 & -0.905 & 0.205 \\
\hline Ineligible/out-of-pocket & -0.430 & 0.266 & -1.88 & $0.06^{* *}$ & 0.036 & -0.951 & 0.091 \\
\hline
\end{tabular}

Obs. $P=0.823529$

Pred. $P=0.870344$ (at $\mathrm{x}$-bar)

Canceled once $=1$; canceled more than once $=0$; Significant at ${ }^{* * *} p<0.01$; ${ }^{* *} p<.05$

$\left.{ }^{*}\right) \mathrm{dF} / \mathrm{dX}$ is for discrete change of dummy variable from 0 to $1 ; z$ and $p>|z|$ are the test of the underlying coefficient being 0

Canceled once $=1$; canceled more than once $=0$ 
retrospectively in Saudi Arabia. We employed maximum likelihood estimation with a probit model to estimate that relationship. Probit model estimations using a maximum likelihood procedure have been widely used in healthcare studies, but few examples will suffice. Probit estimation has previously been used in assessing factors associated with quality of services and demand for health care [21], demand for specialty drugs [22], and association of weight and height with a timing of deciduous tooth emergence [23]. Probit approach has also been used to examine awareness and acceptability of human papillomavirus vaccine [24], and prevalence of total diagnosed and undiagnosed diabetes [25].

Previous studies have shown that the issue of same-day cancelation of surgery cases is common $[4,6,17]$. Previous studies also have shown that cancellations of short-stay cases in hospitals frequently occur, causing burden and challenges for theater and surgical operating time [26-28].

Consistent with other studies [29], our study demonstrated that unavailability of OR time is a common cause of cancelation of same-day surgery. However, our study specifically showed that unavailability of OR time is less likely to be associated with the frequent cancelation of same-day surgery relative to a patient being unwell on the day of surgery. This may imply that frequency of cancelation has to do more with patient-related reasons than the capacity of the facility. Additionally, our study revealed more frequent same-day surgery cancelations for scheduling issues compared with reasons for being unwell on the day of the procedure. Findings of previous studies have attributed scheduling issues to day of surgery cancelation $[3,16,30]$. Moreover, the present study showed that morning session and waiting time of more than $6 \mathrm{~h}$ were associated with less frequent cancelation. The finding with respect to sessions is somewhat intuitive and relevant to local customs and climatic conditions such as high temperatures, which may affect working shifts. There are typically fewer activities during afternoon sessions in the region due to very high temperatures. Although more waiting time inconveniences patients, it appears also to give them hope that the facility may honor their appointments for same-day surgery, hence less frequent cancelation.

Like previous studies, our study found that demographic factors play an important role in determining the frequency of same-day surgery cancelation. For instance, our study suggested that female cancel same-day surgery more frequently than male. Cultural issues in Middle Eastern countries such as male family members having the latitude to decide on the movement of women may explain this result. Limitations on the physical mobility of women and girls provide hindrances for them to successfully access and use health services and affect their health-seeking behaviors [31]. That said, the conclusion of previous studies on gender difference with regard to frequency of cancelation is mixed. While some studies showed a higher proportion of female cancelations [16], others revealed no differences between the frequency of cancelation of males and females [32].

This study indicates that married patients less frequently canceled same-day surgery cases compared with patients whose marital status was unknown or not revealed. This finding may be intuitive and consistent with local cultural practices. For instance, the movement of unmarried or unaccompanied women is limited. A close male relative is crucial for their company including an elective surgery.

Insofar as clinical conditions are concerned, our study illustrated that specialized procedures have higher probabilities of same-day surgery cancelation compared to procedures that are more general. This finding is somewhat in agreement with studies that suggested that because the odds of unavailability of operating time were significantly less in general surgery, there were fewer cancelations compared with more specialized procedures such as orthopedics, otolaryngology, neurosurgery, pediatrics, gynecology, ophthalmology, and dentistry [33]. In addition, our finding is consistent with studies confirming evidence of some specialties being more susceptible to the day of surgery cancelations [34].

Our study potentially adds to the growing literature on same-day surgery in two fundamental ways. The present study is the first such analysis of its kind in Saudi Arabia that employed maximum likelihood estimation with probit model to examine factors associated with the probability of same-day surgery cancelation. Similarly, our study contributes to the understanding of the crucial role of context and local application, especially in the wake of the dearth of studies dealing with the frequency of same-day surgery cancelation in the region. In this context, our study provides workable evidence that we believe is an important strategy for optimizing resource usage and management of same-day surgery cancelations by hospitals in the country and across the region. Resource management and its implication on cost, as pointed out in a recent review, is an area that needs sensitization in Saudi Arabia [35].

\section{Limitations}

It is important, however, to note that our study has some limitations. For instance, there may be biases due to errors of entry, or misclassification, given that the data utilized for the present study is from retrospective medical records. As is common with retrospective studies, we cannot ascertain the existence (or lack thereof) of confounding factors in the data. There are various methods of dealing with such problems, including randomization. We based our study on the availability of retrospective 
data, but such methods are typically applied at the time of study design. Our study did not directly deal with patients, rendering randomization untenable at the start. Additionally, we should note that while our study found an association between the probability of frequency of same-day surgery cancelation and the various factors relating to patient demographics and clinical conditions, we could not establish causality given that the retrospective data were cross-sectional. Moreover, our study was limited to the OR of a single hospital. Perhaps inclusion or comparison with other facilities may exhibit different distributions and associations between variables of interest.

\section{Conclusion}

This study explored the association between the probability of frequency of same-day surgery cancelation and various factors such as patient demographics, time-related variables, healthcare provider reasons for cancelation, and clinical procedures. The study employed a combination of descriptive statistics and maximum likelihood estimation with probit model for inferential analysis. The study found a significant association between the probability of the frequency of same-day surgery cancelations and some key covariates of interest. For example, the present study revealed that facility characteristics-related issues such as availability of operating room time and scheduling do associate with whether or not patients canceled same-day surgery cases. In particular, while reasons of unavailability of OR times were associated with the less frequent cancelation of same-day surgery, scheduling issues were linked to cancelations that are more frequent. In addition, we found that waiting time of more than $6 \mathrm{~h}$ and morning sessions were associated with less frequent cancelation compared to less waiting time and afternoon sessions. Moreover, the study showed evidence of some highly specialized clinical procedures being more susceptible to the day of surgery cancellations compared to general procedures. Further, the study indicated significant gender difference in the frequency of same-day surgery cancelations, with female patients being more likely to cancel same-day surgery appointments.

We draw several implications that we believe are important for hospital operating rooms management, especially on optimal utilization of resources and minimization of same-day surgery cancelations. First, with regard to issues such as scheduling, waiting time, and sessions of operation, hospital facilities need to incorporate patient preferences, reduce waiting time by regularly reviewing their staffing policies, workflows, and shift system. Hospitals should occasionally form task forces to understand, investigate, and establish whether indeed the factors associated with frequency of same-day surgery cancelations are facility-specific, the result of human errors, or even system-wide phenomena. For instance, since scheduling normally should focus on patients rather than providers, understanding these issues further will help facilities institute measures that ensure better care. Moreover, hospitals need to find ways of accommodating or rerouting patients requiring more specialized same-day surgery in order to minimize potential complications, or even death arising from the cancelation of such procedures.

We offer several recommendations that we believe will spur future research. First, there is a need for further research that isolates facility or OR-specific practice style as natural experiments in order to assess the comparative effectiveness of different operating rooms across hospitals in the locality. In addition, although we found other literature in the region linking gender differences in frequency of cancelation to cultural reasons, there is a need for further studies to establish the extent to which such attribution affects demand for health care in the facility or country. Furthermore, in order to address the limitation of retrospective cross-section data, possibly establish causality of the covariates on the frequency of same-day cancelation, we recommend a robust longitudinal study undertaking that follows patients' records over multiple periods. Additionally, in order to deal with retrospective data-related biases and the possibility of the presence of confounding factors, we recommend future studies to consider randomization or other methods of minimizing such challenges when designing studies.

\section{Abbreviations}

DOS: Day of surgery; ECCE: Extracapsular cataract extraction; IOL: Intra Ocular Lens; IRB: Institutional Review Board (IRB); KAIMRC: King Abdullah

International Medical Research Center; KFNGH: King Fahad National Guard Hospital in Riyadh; KMAC: King Abdulaziz Medical City; OR: Operating room; Phaco: Phacoemulsification; SANG: Saudi National Guard

\section{Acknowledgements}

The authors would like to express their thanks and gratitude to King Abdullah International Medical Research Centre (KAIMRC) for providing the partial funds and IRB approval (SP15/148). The authors are also grateful to the Research Committee of the College of Public Health \& Health Informatics, King Saud bin Abdulaziz University for Health Sciences for the initial proposal review. The information and opinions contained in this paper do not necessarily reflect the views or policy of these institutions.

\section{Funding}

The authors would like to express their thanks and gratitude to King Abdullah International Medical Research Center (KAIMRC) for providing the partial funds for this project under research protocol No SP15/148. However, the authors are responsible for the design of the study, the collection, analysis, and interpretation of the data, and the writing of the manuscript.

\section{Availability of data and materials}

Data supporting study findings are available upon request.

\section{Authors' contributions}

OBD is the first author of this study. He guided on the conception and methodology of the study. OBD further performed the statistical analysis and approved the final version for this manuscript for submission. TA is the second author of this paper. He took the responsibilities of data collection 
and cleaning. He was also involved in the initial design of the study, reviewed draft manuscript, and approved the final version for submission.

\section{Authors' information}

Omar B. Da'ar, Ph.D. is an Assistant Professor of Health Economics \& Financing at the Department of Health Systems \& Quality Management College of Public Health and Health Informatics, King Saud Bin Abdulaziz University for Health Sciences: Email: daaro@ksau-hs.edu.sa. He is also an Adjunct Assistant Professor, Graduate School of Professional Studies, St. Mary's University of Minnesota, Minneapolis, MN, USA; Email odaar@smumn.edu: Talal Al-Mutairi, BS, MPH. was graduate student at the Department of Health Systems \& Quality Management, College of Public Health and Health Informatics, King Saud Bin Abdulaziz University for Health Sciences. He was also Bed Coordinator, Cardiac Department, King Fahad Hospital, King Abdulaziz Medical City, National Guard Health Affairs, Riyadh, Saudi Arabia; Email: mr.talal@windowslive.com.

\section{Ethics approval and consent to participate}

The research committee of King Abdullah Medical Research Center (KAIMRC) reviewed this study and granted institutional review board (IRB) under research protocol No SP15/148.

\section{Competing interests}

The authors declare that they have no competing interests.

\section{Publisher's Note}

Springer Nature remains neutral with regard to jurisdictional claims in published maps and institutional affiliations.

\section{Author details}

${ }^{1}$ Department of Health Systems \& Quality Management, College of Public Health \& Health Informatics, King Saud Bin Abdulaziz University for Health Sciences, National Guard Health Affairs (NGHA), Riyadh, Saudi Arabia. ${ }^{2}$ Graduate School of Professional Studies, St. Mary's University of Minnesota, Minneapolis, MN, USA. ${ }^{3}$ King Fahad Hospital, King Abdulaziz Medical City, National Guard Health Affairs (NGHA), Riyadh, Saudi Arabia.

Received: 6 June 2017 Accepted: 29 May 2018

Published online: 15 June 2018

\section{References}

1. Argo JL, Vick CC, Graham LA, Itani KM, Bishop MJ, Hawn MT. Elective surgical case cancellation in the veterans health administration system: identifying areas for improvement. Am J Surg. 2009:198(5):600-6.

2. Chalya PL, Gilyoma JM, Mabula JB, Simbila S, Ngayomela IH, Chandika AB, Mahalu W. Incidence, causes and pattern of cancellation of elective surgical operations in a university teaching hospital in the Lake zone, Tanzania. Afr Health Sci. 2011;11(3):438-43.

3. Kaddoum R, Fadlallah R, Hitti E, El-Jardali F, El Eid G. Causes of cancellations on the day of surgery at a tertiary teaching hospital. BMC Health Serv Res. 2016;16:259

4. Sahraoui A, Elarref M. Bed crisis and elective surgery late cancellations: an approach using the theory of constraints. Qatar Med J. 2014;2014(1):1-11.

5. Seim AR, Fagerhaug T, Ryen SM, Curran P, Saether OD, Myhre HO, Sandberg WS. Causes of cancellations on the day of surgery at two major university hospitals. Surg Innov. 2009;16(2):173-80.

6. Sultan N, Rashid A, Abbas SM. Reasons for cancellation of elective cardiac surgery at Prince Sultan cardiac Centre, Saudi Arabia. J Saudi Heart Assoc. 2012;24(1):29-34.

7. Farasatkish R, Aghdaii N, Azarfarin R, Yazdanian F. Can preoperative anesthesia consultation clinic help to reduce operating room cancellation rate of cardiac surgery on the day of surgery? Middle East J Anaesthesiol. 2009:20(1):93-6.

8. Zafar A, Mufti TS, Griffin S, Ahmed S, Ansari JA. Cancelled elective general surgical operations in Ayub teaching hospital. J Ayub Med Coll Abbottabad. 2007:19(3):64-6.

9. Perroca MG, Jerico Mde C, Facundin SD. Surgery cancelling at a teaching hospital: implications for cost management. Rev Lat Am Enfermagem. 2007; 15(5):1018-24.

10. Dimitriadis PA, lyer S, Evgeniou E. The challenge of cancellations on the day of surgery. Int J Surg. 2013;11(10):1126-30.
11. Basson MD, Butler TW, Verma H. Predicting patient nonappearance for surgery as a scheduling strategy to optimize operating room utilization in a veterans' administration hospital. Anesthesiology. 2006;104(4):826-34.

12. Pollard JB, Olson L. Early outpatient preoperative anesthesia assessment: does it help to reduce operating room cancellations? Anesth Analg. 1999;89(2):502-5.

13. Rai MR, Pandit JJ. Day of surgery cancellations after nurse-led preassessment in an elective surgical Centre: the first 2 years. Anaesthesia. 2003;58(7):692-9.

14. Schofield WN, Rubin GL, Piza M, Lai YY, Sindhusake D, Fearnside MR, Klineberg PL. Cancellation of operations on the day of intended surgery at a major Australian referral hospital. Med J Aust. 2005;182(12):612-5.

15. Griffin X, Griffin D, Berry A, Hunter D. Cancellation of elective surgery any improvement after ten years? Ann R Coll Surg Engl. 2006:88(1):28-30.

16. Singh GC, Agha R, Roberts DR. Cancellations in day-case ENT surgery. Ambul Surg. 2005:12(2):57-60.

17. Dhafar KO, Ulmalki MA, Felemban MA, Mahfouz ME, Baljoon MJ, Gazzaz ZJ, Baig M, Hamish NM, AlThobaiti SA, Al-Hothali FT. Cancellation of operations in Saudi Arabian hospitals: frequency, reasons and suggestions for improvements. Pak J Med Sci. 2015;31(5):1027-32.

18. Mesmar M, Shatnawi NJ, Faori I, Khader YS. Reasons for cancellation of elective operations at a major teaching referral hospital in Jordan. East Mediterr Health J. 2011;17(8):651-5.

19. StataCorp: Stata Statistical Software Release 12. College Station, TX/; StataCorp LP. In.; 2011.

20. Fernando BS, Cannon PS, Mohan M. Cancellation of surgical day cases in an ophthalmic Centre. Acta Ophthalmol. 2009:87(3):357-8.

21. Akin JS, Guilkey DK, Denton EH. Quality of services and demand for health care in Nigeria: a multinomial probit estimation. Soc Sci Med (1982). 1995; 40(11):1527-37

22. Hosseini Jebeli SS, Barouni M, Orojloo PH, Mehraban S. Estimating the marginal effect of socioeconomic factors on the demand of specialty drugs. Glob J Health Sci. 2014;7(2):28-37.

23. Shaweesh Al, Al-Batayneh OB. Association of weight and height with timing of deciduous tooth emergence. Arch Oral Biol. 2017;87:168-71.

24. Do YK, Wong KY. Awareness and acceptability of human papillomavirus vaccine: an application of the instrumental variables bivariate probit model. BMC Public Health. 2012:12:31.

25. Yin M, Augustin B, Shu C, Qin T, Yin P. Probit models to investigate prevalence of Total diagnosed and undiagnosed diabetes among aged 45 years or older adults in China. PLoS One. 2016;11(10):e0164481.

26. Sanjay P, Dodds A, Miller E, Arumugam PJ, Woodward A. Cancelled elective operations: an observational study from a district general hospital. J Health Organ Manag. 2007;21(1):54-8.

27. Smith MM, Mauermann WJ, Cook DJ, Hyder JA, Dearani JA, Barbara DW. Same-day cancellation of cardiac surgery: a retrospective review at a large academic tertiary referral center. J Thorac Cardiovasc Surg. 2014;148(2):721-5.

28. Lacqua MJ, Evans JT. Cancelled elective surgery: an evaluation. Am Surg. 1994;60(11):809-11.

29. Kumar R, Gandhi R. Reasons for cancellation of operation on the day of intended surgery in a multidisciplinary 500 bedded hospital. J Anaesthesiol Clin Pharmacol. 2012;28(1):66-9.

30. Xue W, Yan Z, Barnett R, Fleisher L, Liu R. Dynamics of elective case cancellation for inpatient and outpatient in an academic center. J Anesth Clin Res. 2013:4(5):314.

31. World Health Organization ROftEM. Cross-cutting gender issues in women's health in the eastern Mediterranean. Region. 2007

32. Gonzalez-Arevalo A, Gomez-Arnau Jl, delaCruz FJ, Marzal JM, Ramirez S, Corral EM, Garcia-del-Valle S. Causes for cancellation of elective surgical procedures in a Spanish general hospital. Anaesthesia. 2009;64(5):487-93.

33. Chiu CH, Lee A, Chui PT. Cancellation of elective operations on the day of intended surgery in a Hong Kong hospital: point prevalence and reasons. Hong Kong Med J. 2012;18(1):5-10.

34. Haana V, Sethuraman K, Stephens L, Rosen H, Meara JG. Case cancellations on the day of surgery: an investigation in an Australian paediatric hospital. ANZ J Surg. 2009;79(9):636-40.

35. Da'ar OB, Al Shehri AM. Towards integration of health economics into medical education and clinical practice in Saudi Arabia. Med Teach. 2015; 37(Suppl 1):S56-60. 